\title{
LAW, ETHICS AND MEDICINE
}

\section{Theory and practice of informed consent in the Czech Republic}

\author{
Eva Krizova, Jiri Simek
}

J Med Ethics 2007;33:273-277. doi: 10.1136/jme.2005.015164

The large-scale change of Czech society since 1989 has involved the democratic transformation of the health system. To empower the patient was one important goal of the healthcare reform launched immediately after the Velvet Revolution. The process has been enhanced by the accession of the Czech Republic to the European Union and the adoption of important European conventions regulating the area. The concept of informed consent and a culture of negotiation are being inserted into a traditionally paternalistic culture. Our article describes the current situation on the issue of the communication of information on state of health and treatment, and on the question of the participation of the patient in decisions on treatment. We present empirical results of a public opinion survey on this issue. The results show a still prevailing submissive attitude towards the physicians, despite the fact that the concept of informed consent has become more and more publicly familiar ( $42 \%$ of respondents gave the completely correct answer regarding informed consent). The impact of age, education and sex on answers to the questionnaire was analysed. Men, younger and more educated respondents were more likely to show the autonomous attitude, whereas women, older and less educated people tended to show the traditional submissive attitude. Further, our article raises the question of the cultural and historical background within which the current ethically and legally binding norms (products of western democracies, in fact) are interpreted. The question is how far cultural modifications are tolerable in the practical implementation of universal ethical constructs (informed consent).

See end of article for authors' affiliations

Correspondence to: Correspondence to:
E Krizova, 3rd Faculty of Medicine, Charles University, Ruska 87, 100 00 Praha 10, Czech' Republic; eva.krizova@|f3. cuni.cz

Received

21 November 2005

Revised 28 March 2006

Accepted 30 March 2006
$\mathrm{T}$ he requirement that all treatment takes place with the consent of the patient has been formally applicable in the Czech Republic for many years, since 1966, just like the obligation of the doctor to inform the patient about his or her condition and treatment. The only exceptions are people in immediate danger of death (often unconscious and unable to express their wishes), minors and situations in which a patient presents a danger to himself or to those around him. In these cases, according to Czech legislation that is still in force, the doctor is legally obliged to give treatment against a patient's will or the will of his legal representatives, and the autonomy of the patient may be restricted by a court ruling. Act no
20/1966 Coll. (http://www.mvcr.cz/sbirka/1966/ sb07-66.pdf), "On care for the people's health" Section 23 (Advising the sick person and his consent) states that

The physician is required to advise the sick person, or possibly the members of his family, about the nature of the illness and about any necessary procedures in such a way that these individuals may become active associates during the provision of the therapeutic preventive care.

And that

Examination and therapeutic procedures are carried out with the consent of the sick person, or where this consent may be presumed. If the sick person refuses necessary care despite proper explanations, the attending physician will require a written statement to this effect (a waiver).

These two conditions, formulated more than 35 years ago, cannot be regarded as a sufficient basis for the practice of informed consent in today's sense of the term. The obstacle lies in the wording and the instrumental conditionality of the provision of information. The text of the first paragraph qualifies the obligation to provide the patient with information by linking it to the aim of gaining his agreement to the treatment ("in such a way that these individuals may become...") and so implicitly indicates that the patient's right to information is not absolute and unconditional in itself, but only in connection with the treatment to follow and the patient's cooperation during treatment. The right to information is thus made contingent on the result this information is expected to produce in terms of cooperation between patient and doctor. In the socialist era, it became settled custom that information was filtered through to the patient depending on the needs, readiness and will of the doctor. The socalled "merciful lie" was a widespread practice in cases of unfavourable diagnoses and prognoses. Thus, it was for the doctor to decide whether to provide information, how much, in what form, at what time and in what environment. The natural consequence of such an interpretation is that there are no solid cultural patterns on the information process and no inbuilt communication stereotypes. Communication takes place in a non-transparent way and tends to be minimal. The doctor may even 


\begin{tabular}{|ll|}
\hline $\begin{array}{l}\text { Table 1 } \\
\text { sample }\end{array}$ & Demographic characteristics of the \\
\hline & $\mathbf{n = 1 6 1 9}$ \\
\hline Sex & \\
Males & 48.2 \\
Females & 51.8 \\
Age & \\
$\leqslant 29$ years & 29.8 \\
$30-44$ years & 21.2 \\
$45-64$ years & 32.8 \\
$\geqslant 65$ years & 16.2 \\
Education & 10.7 \\
Primary & 37.4 \\
Vocational training & 42.2 \\
Secondary & 10.7 \\
University & \\
\hline & \\
\hline
\end{tabular}

defend a failure to provide information on the grounds that this protects the patient from the negative consequences of unfavourable information. The doctor is also the one who directs the communication process and controls it. He may therefore block it with impunity. Although the wording of the law recognises the claims of patients to information and participation, de facto even these legal guarantees of the rights of patients were not always observed and respected in full measure; on the contrary, a paternalistic approach to the patient, which also legitimised the non-provision of information, was culturally dominant. Often it was the closest relatives rather than the patient himself who were informed about unfavourable diagnoses and prognoses. The term "informed consent" does not explicitly appear in the legal provisions quoted above, not even today, being from the point of view of content divided between the doctor's obligation to inform the patient in paragraph 1 and consent to treatment in paragraph 2. Since paragraph 1 makes the provision of information instrumental rather than absolute-that is, related to the need to ensure the patient's cooperation in treatment-logically, consent on the basis of incomplete information might be considered invalid.

After 1989, as part of the democratisation of the Czech health service, The charter on the patients rights ${ }^{1}$ was officially adopted in 1992 by the Central Ethical Commission of the Ministry of Health. Another important impulse was the acceptance of the European Convention on Human Rights and Biomedicine of the Council of Europe ${ }^{2}$ in 2001 by the Czech Parliament. The convention has in fact strongly influenced the amendment of Czech legislation on a further two points. One of them is the institution of informed consent for the purposes of research and the other is the patient's right to information contained in its documentation.

As a result, the term informed consent is already explicitly used in current Czech legislation, but only in relation to the

Table 2 How do you understand "informed consent"? Express in your own words

\begin{tabular}{l}
\hline $\begin{array}{l}\text { (a) Entirely correct (filled the criteria of both "informed" and } \\
\text { "consent") }\end{array}$ \\
$\begin{array}{l}\text { (b) Partially correct (fulfilled only one criteria, ie, of "being } \\
\text { informed" or of "consent to treatment") }\end{array}$ \\
$\begin{array}{l}\text { (c) Mistaken (respondent's description wrong, eg, "consent } \\
\text { given to proffered information") }\end{array}$ \\
$\begin{array}{l}\text { (d) Term not understood at all (respondent either did not } \\
\text { answer or had never encountered the term) }\end{array}$ \\
\hline
\end{tabular}

participation of patients in clinical testing of new drugs or procedures. We find the term informed consent in Act no 79/ 1997 on drugs in section 33 (Clinical testing of human drugs) and in section 34 (Protection of subjects of clinical testing). The consent has an obligatory written form, must be dated and signed, must contain detailed information about the nature, relevance, consequences and risks of clinical assessment, must be documented and submitted to competent persons. The emphasis is laid on comprehensible information. Informed consent is also explicitly defined for the purposes of research in Act no $123 / 2000$ on medical devices in the wording of amendments of 2003, section 10.

In Act no 20/1966 Coll. (On care for the people's health), section $27 \mathrm{~b}$ stipulates that clinical testing in humans by the use of methods hitherto not introduced into standard clinical practice may be conducted "only with the written consent of the person on whom the test is to be conducted" and "prior to the giving of consent the person must be properly informed about the nature of the mode of application, period of application and purpose of the not yet introduced method, and also of risks associated therewith", but from the formal point of view the actual term "informed consent" is not mentioned.

The Convention on Human Rights and Biomedicine has also influenced amendments to the Law on Care for the people's health relating to a patient's access to his or her documentation. According to section $67 \mathrm{~b}$ Healthcare Documentation, paragraph 12, the patient has a right "to the provision of all information assembled in the medical documentation...". Some people interpret this as only a right to the information contained in the file-for example, rewritten by the doctor in a new document and not in the file itself. The result of this interpretation is that the patient normally only receives the reprocessed content of his documentation, and does not have access to the authentic data. Another view, which is close to our own, is that a right to all information naturally implies a right to a direct look at one's own file. Practice is very heterogeneous: many doctors do in fact allow patients to look at their files or make photocopies of records, but they see it as a mark of benevolence and not as an obligation. Problems usually only arise in the conflicting situation.

In the medical and the legal communities, therefore, the prevailing situation is one of disharmony between different interpretations. Although it cannot be denied that there is ever more visible progress from a "medicine of silence" to a "medicine of negotiation", the provision of information is by no means a matter of course in every case. While in general it is the doctors who tend to be more reserved towards the newly formulated rights of the patient to complete information, we can see various attitudes among them, and these are probably strongly affected by age group. Doctors of the older generation tend to defend what is known as the "therapeutic privilege" not to speak the whole truth (which may, in line with the convention, be left to national legislations), whereas younger doctors are already more likely to take the patient's right to information for granted. A discrepancy between the needs of the public and the professional attitudes of doctors has been identified in surveys abroad and in the Czech Republic, and shows that, in conflicts of ethical principles, doctors have a strong tendency to prioritise the patient's beneficence at the expense of his or her autonomy. ${ }^{3-6}$

Under pressure from the academic community, patient advocacy groups and European Union institutions, informed consent is gradually being introduced into clinical practice in the Czech Republic. First and foremost, the consent of the patient for all surgical procedures and participation in clinical trials is formally confirmed by a document of informed consent. 
Table 3 In some hospitals, before their operations, patients sign consent documents of the type "I consent to the performance of an operation of the kind and of the extent that the surgeon shall decide according to the need that emerges during the operation." Do you find this kind of formulation acceptable?"

\begin{tabular}{ll}
\hline Definitely yes & $17.9 \%$ \\
Probably yes & $47.8 \%$ \\
Probably no & $24.2 \%$ \\
Definitely no & $10.1 \%$ \\
Modus and median & Probably yes \\
\hline
\end{tabular}

At the formal level, the principle of informed consent is therefore perceived as binding, but on the other hand a great many experiments are being made with regard to its content, and above all it is being made to serve a purpose other than the one for which it was intended. Rather than for the protection of the patient, informed consent has been considered far more important for the legal protection of the doctor. In many health centres, it has increasingly become the practice for patients to be asked for formal signature of consent for surgery just before their operations and without proper explanation; most of them sign. Situations have even been recorded in which the informed consent is formulated as a priori agreement to anything that turns out to be necessary in the course of the operation.

Gaining widespread acceptance in everyday practice of universal ethical norms formulated in academic ivory towers is a complicated social process, ${ }^{7}$ in which different interests clash and the partners have different capacities to defend their interests. It is clear that in a country with a strong paternalist tradition like the Czech Republic, there will be continuing efforts to adapt demands originally formulated as the needs of the patients to requirements that tend to serve doctors instead. In the Czech Republic, the doctor has traditionally been unambiguously the dominant partner, negotiation between the partners has not been an option and communication has been something that tended to consist of no more than a brief monologue by the doctor. The position of the patient was further weakened in socialist society by the universal helplessness of the citizen in the face of the representatives of power.

\section{Empirical survey}

To find out what kind of needs for information Czech citizens have and how the lay public in the Czech Republic sees the concept of informed consent, in 2004, we conducted a survey among the Czech population. Via an agency, we addressed 1619
Table 5 Should a surgeon, during a gynaecological or appendix operation, be allowed to remove an ovary without having obtained the express consent of the patient beforehand?

\begin{tabular}{ll}
\hline Definitely yes & $8.7 \%$ \\
Probably yes & $31.0 \%$ \\
Probably no & $31.7 \%$ \\
Definitely no & $28.7 \%$ \\
Modus and median & Probably no \\
\hline
\end{tabular}

people, a representative set of the population of the Czech Republic (table 1).

The central theme of our survey was the question of informed consent. First, in an open question, we asked whether respondents understood the term and what they thought it meant; in this way, we tested their competence to answer. The free answers were categorised according to whether and how far they corresponded to the criteria of the objective content of the concept of informed consent (table 2).

Almost one-third of respondents did not know how to explain or define the term informed consent (d) in table 2 according to our criteria. Their responses were "I don't know, I haven't heard it before, it means nothing to me, I don't know what it is about, I don't understand the question" and so on. The answers of 3.7\% respondents were categorised as mistaken (c) in table 2. Placed in this group were, for example, answers like "I agree to my family being informed", "agreement with euthanasia", "agreement to the use of personal data", "agreement to the provision of my body for research purposes", "agreement to everything". Just under a quarter of answers $(23.6 \%)$ partly approximated to the correct explanation of the term (b) in table 2, but emphasised only one aspect-for example, the aspect of information ("explanation of state of health", "being informed of the risks of an operation", "being told what to expect after an operation") or of consent ("prior consent to an operation", "consent to a certain treatment", "consent to possible consequences", "the patient is given information and has no option but to consent", "it's that thing that I have to consent to, and by signing I consent to it" ${ }^{\prime \prime}$. These types of answers were classified in the category of partially correct because they put too much stress on the passive position of the patient and did not understand informed consent as a method for the patient's active participation.

The largest proportion of answers, but still only $41.8 \%$, could be considered as generally correct explanations of the term informed consent (a) in table 2 . We considered correct answers as "I agree to treatment after getting an explanation", "that I

Table 4 Polytomous Universal Model, SPSS V.10

\begin{tabular}{|c|c|c|c|c|c|c|}
\hline & \multirow[b]{2}{*}{ Estimate } & \multirow[b]{2}{*}{ SE } & \multirow[b]{2}{*}{ OR } & \multicolumn{2}{|c|}{$95 \% \mathrm{Cl}$ for OR } & \multirow[b]{2}{*}{$\mathrm{p}$ Value } \\
\hline & & & & $\begin{array}{l}\text { Lower } \\
\text { bound }\end{array}$ & $\begin{array}{l}\text { Upper } \\
\text { bound }\end{array}$ & \\
\hline Males (relative to females) & 0.082 & 0.095 & 1.085 & 0.902 & 1.307 & 0.386 \\
\hline $\begin{array}{l}\text { Education (university relative to } \\
\text { primary) }\end{array}$ & -0.632 & 0.203 & 0.532 & 0.357 & 0.791 & 0.002 \\
\hline $\begin{array}{l}\text { Education (secondary relative to } \\
\text { primary) }\end{array}$ & $\circ-0.394$ & 0.163 & 0.674 & 0.490 & 0.929 & 0.016 \\
\hline $\begin{array}{l}\text { Education (vocational relative to } \\
\text { primary) }\end{array}$ & $\circ-0.308$ & 0.164 & 0.735 & 0.533 & 1.013 & 0.060 \\
\hline Age (by 10-year age groups) & 0.090 & 0.030 & 1.094 & 1.041 & 1.162 & 0.001 \\
\hline
\end{tabular}


Table 6 Polytomous Universal Model, SPSS V.10

\begin{tabular}{|c|c|c|c|c|c|}
\hline & \multirow[b]{2}{*}{ Estimate SE } & \multirow[b]{2}{*}{ OR } & \multicolumn{2}{|c|}{$95 \% \mathrm{Cl}$ for OR } & \multirow[b]{2}{*}{ p Value } \\
\hline & & & $\begin{array}{l}\text { Lower } \\
\text { bound }\end{array}$ & $\begin{array}{l}\text { Upper } \\
\text { bound }\end{array}$ & \\
\hline $\begin{array}{l}\text { Males (relative to } \\
\text { females) }\end{array}$ & -0.2000 .093 & 0.819 & 0.682 & 0.983 & 0.032 \\
\hline $\begin{array}{l}\text { Education } \\
\text { (university relative to } \\
\text { primary) }\end{array}$ & 0.0540 .200 & 1.055 & 0.713 & 1.562 & 0.787 \\
\hline $\begin{array}{l}\text { Education } \\
\text { (secondary relative } \\
\text { to primary) }\end{array}$ & 0.0610 .160 & 1.063 & 0.778 & 1.454 & 0.701 \\
\hline $\begin{array}{l}\text { Education } \\
\text { (vocational relative } \\
\text { to primary) }\end{array}$ & 0.0070 .161 & 1.007 & 0.735 & 1.379 & 0.967 \\
\hline $\begin{array}{l}\text { Age (by 10-year } \\
\text { age groups) }\end{array}$ & 0.1400 .030 & 1.150 & 1.094 & 1.209 & $<0.001$ \\
\hline
\end{tabular}

know what the treatment involves and I agree to it", "I understand and consent", "to decide for something knowing what it involves and having been sufficiently informed about it", "I consent to something that has been explained to me in detail and that I have understood". These answers, which we categorised as correct, often contained the requirement for complete information and complete truth (eg, "the doctor gives the patient all the information about his illness and method of operation and subsequent care, and on the basis of that the patient gives written consent", "the doctor told the truth and I agreed", "before I say yes they will provide me with all the information"). Many people in this category were aware that informed consent usually takes written form. Younger and more educated respondents gave correct answers significantly more often.

In view of our finding that in clinical practice informed consent is sometimes interpreted to mean that the patient a priori agrees to anything that may happen in treatment, we were interested to discover how far this particular interpretation was acceptable to people. The question was worded as follows: "In some hospitals, before their operations patients sign consent documents of this type: 'I consent to the performance of an operation of the kind and of the extent that the surgeon shall decide according to the need that emerges during the operation.' Do you find this kind of formulation acceptable?" The answers to this question (table 3 ) show that Czech patients are still ready to submit to the authority of the doctor, and entrust doctors with full responsibility for their state. Almost $2 / 3$ of the respondents supported this vaguely formulated informed agreement, $17.9 \%$ of them without reservation and $47.8 \%$ in the sense of tending to agree with the view. Only $24.2 \%$ tended to disagree and $1 / 10$ were entirely against.

There were no significant differences in terms of gender, but the impact of age and education was documented (table 4, PoLytomous Universal Model procedure introduced in SPSS V.10). The older respondents more often agreed with this "blank" formulation of informed consent. Conversely, people with higher education were more likely to dissent the unrealistic wording.

In another question, we used a specific clinical case (a vignette) to test whether Czech patients were really as tolerant of everything that happened to them during treatment. The question read "Sometimes during gynaecological operations or appendix operations surgeons unexpectedly find it necessary to remove an ovary. Do you think that it is right if surgeon takes out an ovary without the prior express consent of the patient?" Approval of the surgeon's action without the consent of the patient was conspicuously lower (table 5) than in the preceding question. Perhaps curiously, disagreement with the surgeon's action was more frequently expressed by men than by women.

The answers to this question were significantly influenced by the age and gender of respondents (table 6, PoLytomous Universal Model procedure introduced in SPSS V.10). Women tended to express a more submissive attitude to doctors and to permit the procedure, whereas men were more uncompromising. The younger respondents disagreed more often with the hypothetical removal of the ovary, whereas older age groups saw the situation as less problematic from the point of view of the consequences and so were more likely to allow it. The impact of education was not statistically significant.

\section{DISCUSSION AND CONCLUSIONS}

If almost a third of citizens do not know the meaning of the term informed consent and only $42 \%$ are capable of correctly describing both its components, then clearly the term has not yet been fully accepted in the Czech Republic. The willingness of a significant proportion of citizens to agree, in the case of illness, to decisions made by the doctor in the course of an operation also testifies to the surviving strong paternalism in the Czech health service. The fact that citizens emerged as significantly less willing to leave the decision to the doctor in the case of removal of an ovary shows that paternalism has its limits, and that respondents are better able to imagine those limits when confronted with a concrete example. The question is, of course, whether men were expressing a realistic or unrealistic attitude given that this was a situation that could not affect them directly-that is, whether just because it was not an experience they might have, they could express their authentic feelings without fear, or the converse. However, the data provide the evidence on changing attitudes towards a more autonomous one in relation to younger age and higher education. We can also conclude that the patterns in our country are currently in the process of transformation.

The question naturally emerges as to the extent to which informed consent in its practical form is dependent on cultural contexts. On the basis of our experience, we would accept the notion that there are different levels of trust in the decisions of doctors in different regions of Europe, and so different degrees of willingness to delegate the power to make particular decisions to doctors. The signatures of patients on the same kinds of document of informed consent may in fact contain different meanings. Sometimes the patient may be confirming with his or her signature the fact that he or she has been properly informed and therefore agrees with the procedure, but elsewhere this may just be a mere expression of faith that the doctor knows best and is the best judge of what is most beneficial for the patient.

The theory of informed consent ${ }^{8}$ is a product of western democratic civic society, and its basis is respect for the autonomy of every individual and his or her responsibility for freely made decisions. The context in which informed consent is being inserted into the former socialist but also several Mediterranean countries is in many respects different from that of Anglo-Saxon culture. ${ }^{9}$ We must therefore ask how these traditions and customs will affect the implementation of informed consent in practice when neither all doctors nor all patients identify with its principles or indeed know what it is. Well-meant moral imperatives designed to protect individual rights and liberties may in practice have counterproductive effects because they may frequently increase misunderstanding, distrust and insecurity.$^{10}$ If civic initiatives for the defence of patients' rights are weak, paradoxically informed consent may tend to protect the doctor rather than support the free decision of the patient. 
In conclusion, we would like to pose a provocative question: is what is happening an acceptable cultural modification of informed consent which does not violate its basis, or are some cultural variations actually an essential denial of informed consent?

\section{ACKNOWLEDGEMENTS}

We are grateful to the INRES-SONES agency and to Dr Petr Sadilek for collecting and elaborating the empirical data of our survey. We also thank RNDr Marek Malý for his statistical expertise.

\section{Authors' affiliations}

Eva Krizova, Jiri Simek, Institute for Medical Ethics and Nursing, 3rd Faculty of Medicine, Charles University, Prague, Czech Republic

This research project is supported by the Grant Agency of the Czech Republic (GA CR), contract no 406/01/1161 - "Informed consent in the Czech Republic".

Competing interests: None.

\section{REFERENCES}

Haskovcova H. Práva pacientů (The rights of patients). Haviř́ov: Nakladatelství A Krtilové, 1996: 167-8.

2 Convention on Human Rights and Biomedicine. Convention for the protection of human rights and dignity of the human being with regard to the application of biology and medicine. Oviedo: Council of Europe, 1997, http:// conventions.coe.int/Treaty/en/Treaties/Html/164.htm (accessed 16 Feb 2007).

3 Elger BS, Harding TW. Should cancer patients be informed about their diagnosis and prognosis? Future doctors and lawyers differ. J Med Ethics 2002;28:258-65.

4 Oken D. What to tell cancer patients. A study of medical attitudes. JAMA $1961 ; 175: 1120-8$.

5 Fried TR, Stein MD, O'Sullivan PS, et al. Limits of patient autonomy. Physician attitudes and practices regarding life-sustaining treatments and euthanasia. Arch Intern Med 1993;153:722-8.

6 Krizova E. Czech physicians remain hesitant communicators. Bull Med Ethics 2003;187:13-15.

7 Griffiths J. The social working of legal rules. J Legal Pluralism 2003;48:1-84.

8 Beauchamp TL, Childress JF. Principles of medical ethics. New York: Oxford University Press, 1989:74-82.

9 Immacolato M. Informed consent in Italy: a Mediterranean country towards an autonomy-based model. J Int Bioethique 2004;15:187-96.

10 McCabe M, Morgan F, Curley H, etal. The informed consent process in a cross-cultural setting: is the process achieving the intended results? Ethn Dis 2005; 15:300-4.

\section{Save your favourite articles and useful searches}

Use the "My folders" feature to save and organise articles you want to return to quickly- saving space on your hard drive. You can also save searches, which will save you time. You will only need to register once for this service, which can be used for this journal or all BMJ Journals, including the BMJ. 